\title{
Fracture Risks Related to Parity and Breastfeeding Effect in Post-Menopausal Women Aged Sixty and Over: Results from the "Quality of Bone in Lorraine” Register
}

\author{
Demba Diédhiou ${ }^{1,2 *}$, Cédric Baumann ${ }^{3}$, Michel Assane Ndour ${ }^{2}$, Marc Klein $^{1}$, Olivier Morel4, \\ Anna Sarr ${ }^{2}$, Mikaël Agopiantz ${ }^{1,4}$, Georges Weryha ${ }^{1}$ \\ ${ }^{1}$ Department of Endocrinology, University Hospital Center of Nancy, Lorraine, France \\ ${ }^{2}$ Department of Internal Medicine II, University Hospital Center of Dakar, Cheikh Anta Diop University, Dakar, Sénégal \\ ${ }^{3}$ Department of Epidemiology and Clinical Evaluation, University Hospital Center of Nancy, Lorraine, France \\ ${ }^{4}$ Department of Obstetrics and Medical Gynecology, University Hospital Center of Nancy, Lorraine, France \\ Email: *dembadiedhiou1976@gmail.com, c.baumann@chu-nancy.fr, m.klein@chru-nancy.fr, mikael.agopiantz@gmail.com, \\ annasarr@orange.sn, olivier.morel17@gmail.com,g.weryha@chu-nancy.fr
}

How to cite this paper: Diédhiou, D., Baumann, C., Ndour, M.A., Klein, M., Morel, O., Sarr, A., Agopiantz, M. and Weryha, G. (2020) Fracture Risks Related to Parity and Breastfeeding Effect in Post-Menopausal Women Aged Sixty and over: Results from the "Quality of Bone in Lorraine" Register. Open Journal of Internal Medicine, 10, 121-134.

https://doi.org/10.4236/ojim.2020.102013

Received: March 4, 2020

Accepted: April 12, 2020

Published: April 15, 2020

Copyright $\odot 2020$ by author(s) and Scientific Research Publishing Inc. This work is licensed under the Creative Commons Attribution International License (CC BY 4.0).

http://creativecommons.org/licenses/by/4.0/ (c) (i) Open Access

\begin{abstract}
Introduction: The long term effect of accumulation of genital events as repeated pregnancy and longer breastfeeding in bone heath later in women's life is still disputed. The objective was to assess the impact of parity and cumulated duration of breastfeeding on fracture risk in post-menopausal women aged sixty an over. Patients and Methods: It was a leading study from the register "Quality of Bone in Lorraine (QBL)" achieved in the department of endocrinology and osteoporotic disease of Nancy (France). This register included all patients sent for an assessment of the bone mass density from January 1, 2006 to December 31, 2014 (9 years). It was about post-menopausal women aged sixty an over suffering or not from osteoporosis fracture or bone fragility just after the age of 45 . The genital events of patients to their age (from puberty to menopause) as well as the existence of hormone replacement therapy use, parity, and breastfeeding duration were taken into account. The assessment of bone fracture was clinical, radiological or by using the vertebral fracture assessment method. Results: 861 post-menopausal women were included. In comparison to the control group, the fractured population had a mean age of (74.3 \pm 9 vs. $72 \pm 8$ years), a family history of fracture (32.1\% vs. $26 \%$ ), and an average input of calcium ( $2.4 \pm 1$ vs. $2.3 \pm 0$ portions per day). The age at menarche was of $12.8 \pm 1$ years in each group, a mean genital activity duration of ( $36.8 \pm 3$ vs. $37.2 \pm 3$ years), a parity of ( $2.1 \pm 1$ vs. $1.8 \pm 1$ children), a cumulated breastfeeding duration ( $4.2 \pm 16$ vs. $3.1 \pm 5$ months $)$ and an age of
\end{abstract}


menopause of ( $48.6 \pm 4$ vs. $48.6 \pm 4$ years) were respectively found in fractured and witness population. Overall, an osteoporotic fracture has been rediscovered in $50.9 \%$. In multivariate analysis, only a cumulative duration of breastfeeding of 6 months and over was associated with a higher fracture risk $(\mathrm{OR}=1.5[1.1-2.2])$. The impact of parity was not significant $(\mathrm{OR}=1.1[0.7$ 1.8]). Association with obesity was quasi significant ( $\mathrm{OR}=1.3[0.9-1.9]$ ). There was no correlation between the fracture risk and the genital activity duration $(\mathrm{OR}=0.7[0.5-1.0])$, hormone replacement therapy use (OR $=1.0$ [0.8 - 1.4]), daily calcium input $(\mathrm{OR}=0.8[0.6-1.3])$, and age of menarche $(\mathrm{OR}=1.0[0.9-1.1])$. Conclusion: This work confirms a negative impact from 6 months of cumulative breastfeeding. The modest effects observed may be related to the selection of Caucasian patients who live in an economically developed country with a limited number of pregnancies and limited duration of breastfeeding.

\section{Keywords}

Parity, Breastfeeding, Fracture Risk, Menopause

\section{Introduction}

Osteoporosis is an increasingly important health problem with an estimation of more than 200 million people in the world. Osteoporosis is a disease essentially bound to menopause and ageing with fractures due to low energy traumas. It is known as the silent epidemic because it does not manifest until a fracture occurs. At least, $40 \%$ of osteoporotic women will suffer from one or several fragility fractures in their life. Post-menopausal osteoporosis represents $30 \%$ in the United States and in Europe. Despite advances in risk assessment and treatment, osteoporosis is still often either not recognized or untreated [1] [2] [3].

Pregnancy and breastfeeding cause in women an important calcic store loss favoring, in a temporal way, a negative calcic balance which is stabilized by bone resorption [4] [5]. The loss of bone mass during pregnancy and breastfeeding reaches up to $10 \%$ of total bone mass. This phenomenon is however reversible during the weaning [5] [6] [7]. The long term effect of accumulation of genital events as repeated pregnancy and longer breastfeeding in bone heath later in women's life is still disputed [8] [9]. Findings sometimes seem contradictory depending on the series and the countries. According to the systematic review of Diédhiou et al. [10], pregnancy does not seem to be associated with an increased risk of osteoporotic fracture after menopause. The negative impact of $\geq 5$ childbirth in Asiatic sub-population requires future investigations. The objective of this study was to assess the impact of parity and cumulated duration of breastfeeding on fracture risk in post-menopausal women aged sixty and over.

\section{Patients and Methods}

This case-control study was a survey achieved in the department of endocrinol- 
ogy and osteoporotic diseases of Nancy University Hospital Center (France). This department has built up a long experience on diagnosis and treatment of metabolic and endocrine diseases. It includes a clinic for the diagnosis and treatment of osteoporosis and calcic diseases. This center disposes a Hologic Dual-Energy X-ray Absorptiometry in the service since 1996 and receives about 600 patients each year.

Our working base was established by the register "Quality of the Bone in Lorraine (QOL)" of bone mass density follow-up of the patients. This register included all patients sent for an assessment of the bone mass density from January 1, 2006 to December 31, 2014 (9 years). It is about patients received for a follow-up of an incidental or sentinel fracture, a persistent bone painful almost vertebral site, and for classic risk factors of osteoporisis [11]. The bone fracture assessment was clinical, radiological (such as X-ray standard, vertebral CT scan, magnetic resonance imaging and bone scintigraphy) or Dual-Energy X-ray Absorptiometry by the vertebral fracture assessment method. The vertebral fracture assessment results were used in case of vertebral settlement. The protocol was based on measurement of the anterior, middle, and posterior heights of each vertebra. A prevalent vertebral fracture was defined as a reduction of at least $20 \%$ in the height [12]. The bone mineral density expressed in T-Score was evaluated at the lumbar spine and femoral neck.

All the patients included in the register have systematically profited an assessment on the history of bone events, bone mass density with the vertebral fracture assessment method. In cases of bone fracture suspicion or any vertebral settlement, a targeted medical imaging was systematically performed. The reports of x-ray standard, ct-scan and magnetic resonance imaging were carried out in the radiology department by specialized radiologists. The medical records consisted of a systematic collection of clinical and densitometric data.

The cases concern all post-menopausal women aged sixty and over, suffering from an osteoporic or fragility fracture broken out after the age of 45 . The witnesses were recruited in the same population of post-menopausal women aged sixty and over, without any osteoporic fracture, received for a bone mass density assessment. Osteoporosis was defined according to the World Health Organization criterions [13]. Osteoporosis was known as severe in associating one or many fragility fractures at the femoral neck, the humerus, the hip, and the spine or in the presence of three simultaneous costal fractures. The diagnosis of menopause was given by the full and final disappearance of the menstrual bleedings. It becomes premature when it occurred before the age 45 and later beyond the age of 55. The period of the genital activity corresponds to the passing time between menarche and menopause.

Being not concerned in the study, the men's subjects, the women who have the following criteria such as ongoing corticoid therapy with a lengthy blocked dose, treatment by GnRH analogue, anti-cancer treatment by the aromatase inhibitory more than one year ago, metastatic fracture, genetics or metabolic bones' 
disease, a metabolic disease (hyperthyroidism, hyperparathyroidism, and Cushing syndrome), anorexia nervosa including amenorrhea of more than 5 years old, vegetarian diet, early menopause, women who did not agree for an inclusion in the study and unexploited files. The study was designed in accordance with the Helsinki declaration and all participants were informed about the nature, purpose and procedures of the study, and gave their written informed consent.

A trained physician administered a questionnaire to all included participants to identify any history of clinical fractures, gynecological and obstetric history including history of abortions, number of pregnancies, the number of children, self-reported age at menarche and menopause, the existence of hormone replacement therapy use, and the cumulative duration of breastfeeding. The cumulated breastfeeding duration represented the total of breastfeeding durations of each fed child.

We also evaluated the age during the inclusion in the "QOL" register, the body weight, the height and the body Mass Index (BMI). The BMI was worked out on the ratio between the weight in kilogram and the square of height in meter. According to the BMI, the subjects were considered as normal between 18.5 and $24.9 \mathrm{~kg} / \mathrm{m}^{2}$, in overweight between 25 and $29.9 \mathrm{~kg} / \mathrm{m}^{2}$, in obesity beyond $30 \mathrm{~kg} / \mathrm{m}^{2}$ [14]. The other data were related to the lifestyle (cigarette smoking, chronic alcohol intake, physical activity level, daily calcium input) and the risk factors of osteoporosis. These parameters concern a first degree family history of osteoporosis or fracture of the upper extremity of the femur, age of menopause, existence of hormone replacement therapy (it was significant when it had lasted more than 2 years), metabolic disease (diabetes, hyperthyroidism, hyperparathyroidism, and Cushing syndrome), an undernourishment condition or a mental nervosa.

The concerned fracture sites were the lumbar spine, upper extremity of the femur, hip, ribs, wrist, ankle, and humerus. The data of the bone mass density during the first consultation were also recorded. The bone mineral density expressed in T-scores was recorded from the lumbar spine and the femoral neck. The two Dual-Energy X-ray Absorptiometry were from Hologic [QDR 4500 A (S/N 45328) and Discovery (S/N 83097)].

For the statistic analysis, the parameters taken into account from the matching were the age (by 5 years age group), gynecological and obstetric history, body mass index (BMI). The existence of a first degree family history of osteoporosis or fracture of the upper extremity of the femur was also taken into account. The analysis of the data was carried out with "SPSS version 8.0 and Epi Info version 6 for Windows". Quantitative general characteristics of the study were expressed as mean \pm standard deviation, using a t-test for mean comparisons. Qualitative characteristics were expressed in number and frequency, using the chi-square test to analyze the differences between subjects with and without fractures. The previously mentioned risk factors that showed associations between subjects with and without fractures in the univariate analysis were included in a multiple 
logistic regression analysis (age, gynecological and obstetric history, and body mass index, family history of osteoporosis or fracture, lifestyle). The risk was expressed as odd ratio (OR) with $95 \%$ confidence interval (CI) and a $\mathrm{p}$ value.

\section{Results}

\subsection{Epidemiological Data}

In total, 861 postmenopausal women were included with a mean age of $73.09 \pm$ 8.8 years (extreme of 60 and 100 years). A first degree family history of osteoporosis and fracture was found in respectively 169 cases (19.6\%) and 251 cases (29.2\%). Other associated pathologies were diabetes mellitus (9.6\%), active smoking (19.9\%), chronic alcoholism (15.3\%), overweight (23.2\%) and obesity (17.6\%). The physical activity level was slight (26\%), moderate (38.2\%), average (29.2\%), and intense (6.5\%). The average input of calcium was higher than 2 portions per day in 384 cases (44.5\%). Table 1 shows the epidemiological characteristics of the population taken into account.

\subsection{Reproductive Events of Women}

The mean age of menarche was of $12.8 \pm 1$ years (extreme to 10 and 18). The average duration of genital activity was of $37 \pm 3$ years (extreme of 22 and 46 years). This duration was $\geq 40$ years in 207 cases (24\%). The average parity was of $1.9 \pm 1$ child (extreme of 0 and 13 children). The patients were nulliparous (20.4\%), mothers with 1 or 2 children (47\%), and with more than 2 children (32.6\%). Only 11 abortions were found. The average duration of cumulated breastfeeding was of $3.6 \pm 6$ months (extreme of 0 and 46 months). No breastfeeding was found in $44.9 \%$ of the cases. The other cases concerned cumulated

Table 1. Epidemiological characteristics of the population taken into account.

\begin{tabular}{cccc}
\hline \multirow{2}{*}{ Characteristics of patients on admission } & Global sise & Yes & No \\
\cline { 3 - 4 } Sample size & 861 & 439 & 422 \\
Mean age (years) & $73.1 \pm 8$ & $74.3 \pm 9$ & $72 \pm 8$ \\
Mean weight (kg) & $65.8 \pm 13$ & $66.6 \pm 13$ & $65 \pm 13$ \\
Mean BMI (kg/m $\left.{ }^{2}\right)$ & $25.9 \pm 5$ & $26.3 \pm 5$ & $25.5 \pm 5$ \\
Active smoking & $163(19.9 \%)$ & $86(19.6 \%)$ & $77(18.2 \%)$ \\
Chronic alcoholism & $131(15.2 \%)$ & $67(15.3 \%)$ & $64(15.1 \%)$ \\
Family history of fracture & $251(29.2 \%)$ & $141(32.1 \%)$ & $110(26 \%)$ \\
Family history of osteoporisis & $169(19.6 \%)$ & $86(19.5 \%)$ & $83(19.6 \%)$ \\
Diabetes mellitus & $83(9.6 \%)$ & $46(10.4 \%)$ & $37(8.7 \%)$ \\
Hormone replacement therapy & $408(47.3 \%)$ & $210(47.8 \%)$ & $198(46.9 \%)$ \\
Physical activity practise & $638(74 \%)$ & $304(69.2 \%)$ & $334(79.1 \%)$ \\
Mean calcium input (portions) & $2.3 \pm 1$ & $2.4 \pm 1$ & $2.3 \pm 0$ \\
\hline
\end{tabular}


breastfeeding duration from 1 to 6 months (39.1\%), from 7 to 12 months $(9.7 \%)$, of more than 12 months (6.3\%). The mean age of menopause was of $48.6 \pm 4$ years (extreme of 43 and 59 years). This age of menopause was $\geq 50$ years in 423 cases $(49.1 \%)$. The hormone replacement therapy concerned 408 women $(47.3 \%)$. Table 2 shows the reproductive characteristics of the population.

\subsection{Fracture Status}

Osteoporic fracture has been found in 439 cases (50.9\%). It concerned a fracture of lumbar spine in 130 cases (15\%), femoral neck in 75 cases (8.7\%), wrist in 197 cases $(22.8 \%)$, humerus in 48 cases $(5.5 \%)$ and of ribs in 42 cases (4.8\%). Table 3 shows the gynecological characteristics and the antecedent of subjects according to fracture profile.

In univariate analysis, a cumulated lactation duration $\geq 6$ months and a parity $\geq 3$ children were associated with an increased fracture risk respectively with an $(\mathrm{OR}=1.6[1.1-2.2])$ and $(\mathrm{OR}=1.5[1.0-2.3])$. In a multiple logistic regression analysis, only a cumulated breastfeeding duration of 6 months or more was associated with a higher fracture risk $(\mathrm{OR}=1.5[1.1-2.2])$. The impact of parity was not significant $(\mathrm{OR}=1.1[0.7-1.8])$. The association with obesity significantly get closer $(\mathrm{OR}=1.3[0.9-1.9])$. There was not any significant correlation between the fracture risk and the other following parameters: genital activity pe$\operatorname{riod}(\mathrm{OR}=0.7[0.5-1.0])$, hormone replacement therapy $(\mathrm{OR}=1.0[0.8-1.4])$, daily calcium input $(\mathrm{OR}=0.8[0.6-1.3])$, chronic alcoholism $(\mathrm{OR}=1.0[0.7$ $1.5])$, smoking $(\mathrm{OR}=1.1[0.8-1.6])$, age at menarche $(\mathrm{OR}=1.0[0.9-1.1])$. Table 4 shows the level of correlation between the fracture risk and the gynecological factors.

\section{Discussion}

In the gestational period and during breastfeeding, the mother provides 200 to

Table 2. Reproductive characteristics of our population under consideration.

\begin{tabular}{cccc}
\hline & & \multicolumn{2}{c}{ Fracture statut } \\
Characteristics of patients on admission & Global size & Yes & No \\
\cline { 3 - 4 } Sample size & 861 & 439 & 422 \\
Mean age at menopause (year) & $48.6 \pm 4$ & $48.6 \pm 4$ & $48.6 \pm 4$ \\
Age of menopausal $\geq 50$ years & $423(49.1 \%)$ & $197(44.8 \%)$ & $226(53.5 \%)$ \\
Mean age at menarche (years) & $12.8 \pm 1$ & $12.8 \pm 1$ & $12.8 \pm 1$ \\
Mean duration of genital activity (years) & $37 \pm 3$ & $36.8 \pm 3$ & $37.2 \pm 3$ \\
Duration of genital activity $\geq 40$ years & $207(24 \%)$ & $91(20.7 \%)$ & $116(27.5 \%)$ \\
Mean parity & $1.9 \pm 1$ & $2.1 \pm 1$ & $1.8 \pm 1$ \\
Parity $\geq 2$ children & $280(32.6 \%)$ & $152(34.6 \%)$ & $128(30.3 \%)$ \\
Mean duration of breastfeeding (months) & $3.6 \pm 6$ & $4.2 \pm 6$ & $3.1 \pm 5$ \\
Hormone replacement therapy & $408(47.3 \%)$ & $210(47.8 \%)$ & $198(46.9 \%)$ \\
\hline
\end{tabular}


Table 3. Gynecological profile and antecedent of subjects according to fracture profile.

\begin{tabular}{|c|c|c|c|c|}
\hline \multicolumn{2}{|c|}{$\begin{array}{l}\text { Characteristics of patients } \\
\text { on admission }\end{array}$} & All fractures & $\begin{array}{l}\text { Vertebral } \\
\text { fractures }\end{array}$ & Femoral fractures \\
\hline \multicolumn{2}{|l|}{ Sample size } & $439 / 861$ & 130 & 75 \\
\hline \multicolumn{2}{|l|}{ Femoral osteoporosis } & $86(19.6 \%)$ & $50(38.5 \%)$ & $10(13.3 \%)$ \\
\hline \multicolumn{2}{|l|}{ Family history of fracture } & $141(32.1 \%)$ & $50(38.5 \%)$ & $2128 \%)$ \\
\hline \multirow[t]{2}{*}{ Parity } & $<2$ children & $162(37 \%)$ & $51(39.2 \%)$ & $27(36 \%)$ \\
\hline & $\geq 2$ children & $277(63 \%)$ & $79(60.7 \%)$ & $48(64 \%)$ \\
\hline \multirow[t]{2}{*}{ Breastfeeding } & $<3$ months & $248(56.5 \%)$ & $78(60 \%)$ & $37(49.3 \%)$ \\
\hline & $\geq 3$ months & $191(43.5 \%)$ & $52(40 \%)$ & $38(50.7 \%)$ \\
\hline \multirow[t]{2}{*}{ Genital activity duration } & $<40$ years & $347(79 \%)$ & $105(80.8 \%)$ & $62(82.7 \%)$ \\
\hline & $\geq 40$ years & $92(21 \%)$ & $25(19.2 \%)$ & $13(17.3 \%)$ \\
\hline \multirow[t]{2}{*}{ Age at menopause } & $<50$ years & $333(75.9 \%)$ & $99(76.1 \%)$ & $59(78.7 \%)$ \\
\hline & $\geq 50$ years & $106(24.1 \%)$ & $31(23.8 \%)$ & $16(21.3 \%)$ \\
\hline \multirow{2}{*}{$\begin{array}{l}\text { Without hormone } \\
\text { replacement therapy }\end{array}$} & Non & $229(52.1 \%)$ & $72(55.4 \%)$ & $49(65.3 \%)$ \\
\hline & Yes & $210(47.8 \%)$ & $58(44.6 \%)$ & $26(34.7 \%)$ \\
\hline \multirow[t]{2}{*}{ Diabetes mellitus } & Yes & $46(10.5 \%)$ & $11(8.5 \%)$ & $7(9.3 \%)$ \\
\hline & No & $393(89.5 \%)$ & $119(91.5 \%)$ & $68(90.7 \%)$ \\
\hline \multicolumn{2}{|l|}{ Active smoking } & $88(20 \%)$ & $26(20 \%)$ & $8(10.6 \%)$ \\
\hline \multicolumn{2}{|l|}{ Chronic alcoholism } & $68(15.5 \%)$ & $17(13 \%)$ & $11(14.6 \%)$ \\
\hline
\end{tabular}

Table 4. Factors associated with the probability of fracture.

\begin{tabular}{|c|c|c|c|c|}
\hline \multirow{2}{*}{ Parameters Studied } & Size & Fracture & $\begin{array}{l}\text { Bivariate } \\
\text { analysis }\end{array}$ & $\begin{array}{c}\text { Multivariate } \\
\text { analysis }\end{array}$ \\
\hline & $\mathbf{N}$ & N (\%) & OR (min-max) & OR (min-max) \\
\hline \multicolumn{5}{|c|}{ Genital activity periods (years) } \\
\hline$\leq 35$ & 269 & $146(54.3 \%)$ & 1 & 1 \\
\hline $36-39$ & 380 & $197(51.9 \%)$ & $0.9(0.6-1.3)$ & $0.9(0.6-1.3)$ \\
\hline$\geq 40$ & 207 & $91(44.0 \%)$ & $0.7(0.5-1.0)$ & $0.7(0.5-1.0)$ \\
\hline \multicolumn{5}{|l|}{ Parity (children) } \\
\hline 0 & 176 & $80(45.5 \%)$ & 1 & 1 \\
\hline $1-3$ & 578 & $291(50.9 \%)$ & $1.2(0.8-1.8)$ & $1.2(0.8-1.8)$ \\
\hline$\geq 4$ & 107 & $64(59.8 \%)$ & $1.5(1.0-2.3)^{*}$ & $1.1(0.7-1.8)$ \\
\hline \multicolumn{5}{|l|}{ Lactation (months) } \\
\hline $0-1$ & 438 & $212(48.4 \%)$ & 1 & 1 \\
\hline $2-5$ & 206 & $94(45.6 \%)$ & $0.9(0.6-1.2)$ & $0.9(0.6-1.2)$ \\
\hline$\geq 6$ & 217 & $129(59.4 \%)$ & $1.6(1.1-2.2)^{*}$ & $1.5(1.0-2.1)^{*}$ \\
\hline \multicolumn{5}{|l|}{ Body mass index $\left(\mathrm{Kg} / \mathrm{m}^{2}\right)$} \\
\hline$\leq 25$ & 439 & $207(47.2 \%)$ & 1 & 1 \\
\hline
\end{tabular}


Continued

\begin{tabular}{|c|c|c|c|c|}
\hline$>25$ & 409 & $220(53.9 \%)$ & $1.3(0.9-1.8)$ & $1.3(0.9-1.8)$ \\
\hline \multicolumn{5}{|c|}{ Hormone replacement therapy } \\
\hline Non & 453 & $227(50.1 \%)$ & 1 & \\
\hline Oui & 408 & $208(51.0 \%)$ & $1.0(0.8-1.4)$ & \\
\hline \multicolumn{5}{|c|}{ Smoking } \\
\hline Yes & 698 & $349(50.0 \%)$ & 1 & \\
\hline No & 163 & $86(52.8 \%)$ & $1.1(0.8-1.6)$ & \\
\hline \multicolumn{5}{|c|}{ Alcoholism } \\
\hline Yes & 729 & $368(50.5 \%)$ & 1 & \\
\hline No & 131 & $67(51.1 \%)$ & $1.0(0.7-1.5)$ & \\
\hline \multicolumn{5}{|c|}{ Daily calcium intake (portion) } \\
\hline $0-1$ & 424 & $223(52.6 \%)$ & 1 & \\
\hline$\geq 2$ & 437 & $212(48.4 \%)$ & $0.9(0.6-1.2)$ & \\
\hline
\end{tabular}

NB: univariate analysis was included in a multiple logistic regression analysis (age, gynecological and obstetric history, and body mass index, family history of osteoporosis or fracture, lifestyle).

$300 \mathrm{mg}$ of calcium daily for bone growth in the fetus and newborn. The supply of this calcium is provided by bone resorption [4] [5] [6] [7]. Fragility fractures have been reported in the peripartum and especially in primiparous women. This situation appears to be related to pre-existing fragility or excessive bone resorption in the mother [15] [16] [17]. However, this situation is reversible after weaning. Our study reports a risk of osteoporotic fracture proportionally increased with the cumulative duration of breastfeeding. Parity is deleterious but not significant in multivariate analysis.

The negative impact of breastfeeding on the risk of postmenopausal fracture was $50 \%(\mathrm{OR}=1.5[1.1-2.1])$. Clinically, some recent studies confirm our results in terms of increased postmenopausal fracture risk. In all these studies, the risk appears only after 6 months cumulative lactation. The impact was greater in trabecular bone [18] [19] [20]. In two Korean studies, the risk of vertebral and fragility fracture were respectively to $0.15 \%(\mathrm{OR}=1.015[1.001-1.030])$ at 6 months of lactation [18], up to $69 \%(\mathrm{HR}=1.69$ [1.08 - 2.66]) beyond 8 months of lactation [19]. Bolzetta et al. [20], in a retrospective study of 752 Italian women, reported a doubling vertebral fracture risk $(\mathrm{OR}=2.12[1.14-5.38], \mathrm{p}=0.04)$ after only 18 months of lactation.

From a physiopathological point of view, these effects are explained by a transient excess of resorption and bone loss secondary to hyper secretion of PTHrp and an estrogenic impregnation deficit that evolves in parallel with lactation [21] [22] [23]. We believe that extended or repeated periods of lactation may lead to transient and deep loss of bone mass with probably incomplete recovery.

This hypothesis is consistent with recent data from the case-control study of bone micro architecture before, during, and 2.6 years after weaning. In this study, 
Bjørnerem et al. [24] reported an irreversible deterioration of micro architecture in relation to lactation. Exclusive breastfeeding for 5 months increased cortical porosity by $0.6 \%$, reduced the matrix mineralization density by $0.26 \%$, the trabecular number by $0.22 / \mathrm{mm}$ and increased trabecular separation by $0.07 \mathrm{~mm}$ (all $\mathrm{p}<0.001)$. Compared to the state before lactation, the 2.6 years after weaning found a high cortical porosity of $0.58 \mathrm{DS}$, a low matrix mineralization density of 1.28 DS, and a greater trabecular separation of 1.06 DS. On the other hand, the bone mineral density assessment in 1486 Turkish menopausal women reported both lower lumbar and femoral bone mass correlated with duration of breastfeeding [25].

However, the majority of studies in the literature did not report significant bone impact in relation to lactation [26]-[36]. Most of them did not adopt a gradual impact assessment methodology of the lactation according to its cumulative duration. This could lead to an underestimation of the fracture risk for extended periods of lactation. In the meta-analysis of Duan et al. [8], the authors reported a possible reduction in the risk of fracture with the duration of lactation. The cumulative relative risk of osteoporotic fracture, hip fracture and wrist fracture was respectively of $16 \%(\mathrm{OR}=0.84$ [0.67 - 1.05]), 28\% (OR $=0.72$ [0.52 $0.99])$, and $18 \%(\mathrm{OR}=0.82$ [0.56 - 1.19]). This risk decreased by $0.9 \%$ and $1.2 \%$ per month of breastfeed respectively for the osteoporotic and hip fracture.

Only three studies reported a significant reduction in fracture risk essentially on cortical bone. Bjørnerem et al. [37] found a reduction in the risk of hip and fragility fracture by $50 \%$ and $27 \%$ respectively. This reduction in the risk of hip fracture occurred only after 13 months of lactation $(\mathrm{OR}=0.28[0.10-0.82])$ and decreased by $13 \%$ for every additional 6 months of lactation [38]. A 39\% reduced risk of wrist fracture $(\mathrm{OR}=0.61[0.40-0.94])$ was reported by Mallmin et al. [39]. The positive effect was already found by Wiklund et al. [40], who found an increase in hip and tibia bone strength in women with 33 cumulative months of lactation. This possible bone protection could be explained by already known mechanical phenomena. The permissive effect of lactation associated with estrogen deficiency plays an important role in increasing bone volume. This promotes an increase in bone diameter by increasing periosteal apposition and endosteal resorption [23] [40] [41] [42].

The torsional and flexural mechanical strength of a hollow cylinder increases exponentially with its diameter for a constant quantity of material. This applies to the diaphyseal bone that undergoes a beneficial transformation during pregnancy for a constant or even slightly diminished of bone mineral density [40] [43] [44]. This is consistent with the findings of Henderson et al. [45] on the post-menopausal densitometric outcome. The authors reported that in $30 \mathrm{mul}$ tiparous mothers with 6 or more children, postmenopausal osteoporotic risk was unaffected by multiple new pregnancies that occurred during lactation and regardless of the length of lactation.

The effect of parity on the risk of osteoporotic fracture is not significant in 
multivariate analysis $(\mathrm{OR}=1.1[0.7-1.8])$. In the systematic review of Diédhiou et al. [10] the authors concluded a neutral or slightly positive impact of parity on fracture risk. In fact, only 3 out of 29 studies reported an increased risk [46] [47] [48]. In multivariate analysis, the risk of fracture was associated with parity $\geq 5$ children in two studies with respectively a $\mathrm{HR}=1.65(1.06-2.56)[48]$ and $\mathrm{RR}=$ 2.53 (1.07 - 6.68) [48].

On the other hand, studies essentially reported a $6 \%$ to $50 \%$ reduction in the risk of vertebral and non-vertebral fractures and that this protection increased with parity [29] [30] [49]-[55]. A reduction in the risk of femoral neck fracture of $8 \%$ to $10 \%$ per child was reported by Michaelsson et al. [29] and Hillier et al. [52]. Honkanen et al [50] in a large series of 1.1798 pre and postmenopausal women found $30 \%$ reduction ( $\mathrm{HR}=0.71[0.52-0.97]$ ) of the risk of wrist fracture. In the meta-analysis of Wang et al. [9], the risk of both osteoporotic and femoral neck fracture was reduced by $11 \%$ and $26 \%$, respectively, in women with at least one child. At the femoral neck, the reduction was $12 \%$ for each additional birth.

\section{Limitations of the Study}

1) The study was conducted in university hospital. It may not represent the community situation which is important in terms of knowledge and practice.

2) This is a single center study. Large scale multicenter study is needed to represent the national situation.

3) This is a retrospective study conducted from patient's files. Only the complete files were included which makes a loss of data.

4) This kind of work doesn't require in our country the approval of ethic committee because it is a retrospective work on patient's file.

\section{Conclusion}

This work confirms the achievements of the literature. It shows the absence of a negative effect of parity and a negative impact from 6 months of cumulative breastfeeding. The modest effects observed may be related to the insufficient power of studies or the selection of Caucasian patients who live in an economically developed country with a limited number of pregnancies and limited duration of breastfeeding. The next step in this work will be its repetition in sub-Saharan Africa with large multiparous, where breastfeeding is often used as a contraceptive method.

\section{Conflicts of Interest}

The authors declare no conflicts of interest regarding the publication of this paper.

\section{References}

[1] Melton, L.J., Chrischilles, E.A., Cooper, C., Lane, A.W. and Riggs, B.L. (1992) Pers- 
pective: How Many Women Have Osteoporosis? Journal of Bone and Mineral Research, 7, 1005-1010. https://doi.org/10.1002/jbmr.5650070902

[2] Silva, M.J. and Gibson, L.J. (1997) Modeling the Mechanical Behavior of Vertebral Trabecular Bone: Effects of Age-Related Changes in Microstructure. Bone, 21, 191-199. https://doi.org/10.1016/S8756-3282(97)00100-2

[3] Currey, J.D. (1999) What Determines the Bending Strength of Compact Bone? Journal of Experimental Biology, 202, 2495-2503.

[4] Prentice, A. (2000) Calcium in Pregnancy and Lactation. Annual Review of Nutrition, 20, 249-272. https://doi.org/10.1146/annurev.nutr.20.1.249

[5] Ensom, M.H., Liu, P.Y. and Stephenson, M.D. (2002) Effect of Pregnancy on Bone Mineral Density in Healthy Women. Obstetrical \& Gynecological Survey, 57, 99-111. https://doi.org/10.1097/00006254-200202000-00022

[6] Karlsson, M.K., Ahlborg, H.G. and Karlsson, C. (2005) Female Reproductive History and the Skeleton: A Review. BJOG: An International Journal of Obstetrics \& Gynaecologyl, 112, 851-856. https://doi.org/10.1111/j.1471-0528.2005.00571.x

[7] Bezerra, F.F., Mendonça, L.M., Lobato, E.C., O’Brien, K.O. and Donangelo, C.M. (2004) Bone Mass Is Recovered from Lactation to Post-Weaning in Adolescent Mothers with Low Calcium Intakes. The American Journal of Clinical Nutrition, 80, 1322-1326. https://doi.org/10.1093/ajcn/80.5.1322

[8] Duan, X., Wang, J. and Jiang, X. (2016) A Meta-Analysis of Breastfeeding and Osteoporotic Fracture Risk in the Females. Osteoporosis International, 28, 495-503. https://doi.org/10.1007/s00198-016-3753-x

[9] Wang, Q., Huang, Q., Zeng, Y., Liang, J.J., Liu, S.Y., Gu, X. and Liu, J.A. (2016) Parity and Osteoporotic Fracture Risk in Postmenopausal Women: A Dose-Response Meta-Analysis of Prospective Studies. Osteoporosis International, 27, 319-330. https://doi.org/10.1007/s00198-015-3351-3

[10] Diédhiou, D., Weryha, G., Angelousi, A., et al. (2017) Impact of Parity on Fracture Risk after Menopause: A Systematic Review. HSOA Journal of Human Endocrinology, 2, 009. https://doi.org/10.24966/HHE-9640/10009

[11] Kanis, J.A., Oden, A., Johnell, O., et al. (2007) The Use of Clinical Risk Factors Enhances the Performance of BMD in the Prediction of Hip and Osteoporotic Fractures in Men and Women. Osteoporosis International, 18, 1033-1046. https://doi.org/10.1007/s00198-007-0343-y

[12] Genant, H.K., Li, J., Wu, C.Y. and Shepherd, J.A. (2000) Vertebral Fractures in Osteoporosis: A New Method for Clinical Assessment. Journal of Clinical Densitometry, 3, 281-290. https://doi.org/10.1385/JCD:3:3:281

[13] Riggs, B.L., Melton, L.J., Robb, R.A., et al. (2004) Population-Based Study of Age and Sex Differences in Bone Volumetric Density, Size, Geometry and Structure at Different Skeletal Sites. Journal of Bone and Mineral Research, 19, 1945-1954. https://doi.org/10.1359/jbmr.040916

[14] Cole, T.J., Bellizzi, M.C., Flegal, M. and Dietz, W.H. (2000) Establishing a Standard Definition for Child Overweight and Obesity Worldwide: International Survey. BMJ, 320, 1240-1243. https://doi.org/10.1136/bmj.320.7244.1240

[15] Black, A.J., Reid, R., Reid, D.M., MacDonald, A.G. and Fraser, W.D. (2003) Effect of Pregnancy on Bone Mineral Density and Biochemical Markers of Bone Turnover in a Patient with Juvenile Idiopathic Osteoporosis. Journal of Bone and Mineral Research, 18, 167-171. https://doi.org/10.1359/jbmr.2003.18.1.167

[16] Peris, P., Guañabens, N., Monegal, A., et al. (2002) Pregnancy Associated Osteoporosis: The Familial Effect. Clinical and Experimental Rheumatology, 20, 697-700. 
[17] Anai, T., Tomiyasu, T., Arima, K. and Miyakawa, I. (1999) Pregnancy-Associated Osteoporosis with Elevated Levels of Circulating Parathyroid Hormone-Related Protein: A Report of Two Cases. Journal of Obstetrics and Gynaecology Research, 25, 63-67. https://doi.org/10.1111/j.1447-0756.1999.tb01124.x

[18] Hwang, I.R., Choi, Y.K., Lee, W.K., et al. (2016) Association between Prolonged Breastfeeding and Bone Mineral Density and Osteoporosis in Postmenopausal Women: KNHANES 2010-2011. Osteoporosis International, 27, 257-265. https://doi.org/10.1007/s00198-015-3292-x

[19] Ahn, S.K., Kam, S. and Chun, B.Y. (2014) Incidence of and Factors for Self-Reported Fragility Fractures among Middle-Aged and Elderly Women in Rural Korea: An 11-Year Follow-Up Study. Journal of Preventive Medicine \& Public Health, 47, 289-297. https://doi.org/10.3961/jpmph.14.020

[20] Bolzetta, F., Veronese, N., De Rui, M., et al. (2014) Duration of Breastfeeding as a Risk Factor for Vertebral Fractures. Bone, 68, 41-45.

https://doi.org/10.1016/j.bone.2014.08.001

[21] Carneiro, R.M., Prebehalla, L., Tedesco, M.B., et al. (2010) Lactation and Bone Turnover: A Conundrum of Marked Bone Loss in the Setting of Coupled Bone Turnover. The Journal of Clinical Endocrinology \& Metabolism, 95, 1767-1776. https://doi.org/10.1210/jc.2009-1518

[22] VanHouten, J.N., Dann, P., Stewart, A.F., et al. (2003) Mammary-Specific Deletion of Parathyroid Hormone-Related Protein Preserves Bone Mass during Lactation. Journal of Clinical Investigation, 112, 1429-1436. https://doi.org/10.1172/JCI200319504

[23] VanHouten, J.N. and Wysolmerski, J.J. (2003) Low Estrogen and High Parathyroid Hormone-Related Peptide Levels Contribute to Accelerated Bone Resorption and Bone Loss in Lactating Mice. Endocrinology, 144, 5521-5529. https://doi.org/10.1210/en.2003-0892

[24] Bjørnerem, A., Ghasem-Zadeh, A., et al. (2016) Irreversible Deterioration of Cortical and Trabecular Microstructure Associated with Breastfeeding. Journal of Bone and Mineral Research, 32, 676-680. https://doi.org/10.1002/jbmr.3018

[25] Dursun, N., Akin, S., Dursun, E., Sade, I. and Korkusuz, F. (2006) Influence of Duration of Total Breast-Feeding on Bone Mineral Density in a Turkish Population: Does the Priority of Risk Factors Differ from Society to Society? Osteoporosis International, 17, 651-655. https://doi.org/10.1007/s00198-005-0029-2

[26] Chan, H.H., Lau, E.M., Woo, J., Lin, F., Sham, A. and Leung, P.C. (1996) Dietary Calcium Intake, Physical Activity and the Risk of Vertebral Fracture in Chinese. Osteoporosis International, 6, 228-232. https://doi.org/10.1007/BF01622739

[27] Johnell, O., Gullberg, B., Kanis, J.A., et al. (1995) Risk Factors for Hip Fracture in European Women: The MEDOS Study. Mediterranean Osteoporosis Study. Journal of Bone and Mineral Research, 10, 1802-1815. https://doi.org/10.1002/jbmr.5650101125

[28] Clark, P., DeLa Pena, F., Gomez-Garcia, F., Orozco, J.A. and Tugwell, P. (1998) Risk Factors for Osteoporotic Hip Fractures in Mexicans. Archives of Medical Research, 29, 253-257.

[29] Michaëlsson, K., Baron, J.A., Farahmand, B.Y. and Ljunghall, S. (2001) Influence of Parity and Lactation on Hip Fracture Risk. American Journal of Epidemiology, 153, 1166-1172. https://doi.org/10.1093/aje/153.12.1166

[30] Cure-Cure, C., Cure-Ramírez, P., Terán, E. and López-Jaramillo, P. (2002) Bone-Mass Peak in Multiparity and Reduced Risk of Bone-Fractures in Menopause. Interna- 
tional Journal of Gynecology \& Obstetrics, 76, 285-291. https://doi.org/10.1016/S0020-7292(01)00583-5

[31] Naves, M., Diaz-Lopez, J.B., Gomez, C., Rodriguez-Rebollar, A. and Cannata-Andia, J.B. (2005) Determinants of Incidence of Osteoporotic Fractures in the Female Spanish Population Older than 50. Osteoporosis International, 16, 2013-2017. https://doi.org/10.1007/s00198-005-1983-4

[32] Mori, T., Ishii, S., Greendale, G.A., et al. (2015) Parity, Lactation, Bone Strength, and 16-Year Fracture Risk in Adult Women: Findings from the Study of Women's Health across the Nation (SWAN). Bone, 73, 160-166.

https://doi.org/10.1016/j.bone.2014.12.013

[33] Lambrinoudaki, I., Flokatoula, M., Armeni, E., et al. (2015) Vertebral Fracture Prevalence among Greek Healthy Middle-Aged Postmenopausal Women: Association with Demographics, Anthropometric Parameters, and Bone Mineral Density. The Spine Journal, 15, 86-94. https://doi.org/10.1016/j.spinee.2014.07.021

[34] Hoffman, S., Grisso, J.A., Kelsey, J.L., Gammon, M.D. and O’Brien, L.A. (1993) Parity, Lactation and Hip Fracture. Osteoporosis International, 3, 171-176. https://doi.org/10.1007/BF01623672

[35] Cumming, R.G. and Klineberg, R.J. (1993) Breastfeeding and Other Reproductive Factors and the Risk of Hip Fractures in Elderly Women. International Journal of Epidemiology, 22, 684-691. https://doi.org/10.1093/ije/22.4.684

[36] Alderman, B.W., Weiss, N.S., Daling, J.R., Ure, C.L. and Ballard, J.H. (1986) Reproductive History and Postmenopausal Risk of Hip and Forearm Fracture. American Journal of Epidemiology, 124, 262-267. https://doi.org/10.1093/oxfordjournals.aje.a114384

[37] Bjørnerem, A., Ahmed, L.A., Jørgensen, L., Størmer, J. and Joakimsen, R.M. (2011) Breastfeeding Protects against Hip Fracture in Postmenopausal Women: The Tromsø Study. Journal of Bone and Mineral Research, 26, 2843-2850. https://doi.org/10.1002/jbmr.496

[38] Huo, D., Lauderdale, D.S. and Li, L. (2003) Influence of Reproductive Factors on Hip Fracture Risk in Chinese Women. Osteoporosis International, 14, 694-700. https://doi.org/10.1007/s00198-003-1429-9

[39] Mallmin, H.S., Ljunghall, S., Persson, I. and Bergström, R. (1994) Risk Factors for Fractures of the Distal Forearm: A Population-Based Case-Control Study. Osteoporosis International, 4, 298-304. https://doi.org/10.1007/BF01622186

[40] Wiklund, P.K., Xu, L., Wang, Q., et al. (2012) Lactation Is Associated with Greater Maternal Bone Size and Bone Strength Later in Life. Osteoporosis International, 23, 1939-1945. https://doi.org/10.1007/s00198-011-1790-Z

[41] Chapman, D.J. (2012) Longer Cumulative Breastfeeding Duration Associated with Improved Bone Strength. Journal of Human Lactation, 28, 18-19. https://doi.org/10.1177/0890334411433573

[42] Streeten, E.A., Ryan, K.A., McBride, D.J., Pollin, T.I., Shuldiner, A.R. and Mitchell, B.D. (2005) The Relationship between Parity and Bone Mineral Density in Women Characterized by a Homogeneous Lifestyle and High Parity. The Journal of Clinical Endocrinology \& Metabolism, 90, 4536-4541. https://doi.org/10.1210/jc.2004-1924

[43] Schnatz, P.F., Marakovits, K.A. and O’Sullivan, D.M. (2010) Assessment of Postmenopausal Women and Significant Risk Factors for Osteoporosis. Obstetrical \& Gynecological Survey, 65, 591-596.

https://doi.org/10.1097/OGX.0b013e3181fc6d30 
[44] Seeman, E. (2002) Pathogenesis of Bone Fragility in Women and Men. The Lancet, 359, 1841-1850. https://doi.org/10.1016/S0140-6736(02)08706-8

[45] Henderson, P.H., Sowers, M., Kutzko, K.E. and Jannausch, M.L. (2000) Bone Mineral Density in Grand Multiparous Women with Extended Lactation. American Journal of Obstetrics \& Gynecology, 182, 1371-1377. https://doi.org/10.1067/mob.2000.107468

[46] Cauley, J.A., Wu, L.L., Wampler, N.S., et al. (2007) Clinical Risk Factors for Fractures in Multi-Ethnic Women: The Women's Health Initiative. Journal of Bone and Mineral Research, 22, 1816-1826. https://doi.org/10.1359/jbmr.070713

[47] El-Maghraoui, A., Rezqi, A., Mounach, A., Achemlal, L., Bezza, A. and Ghozlani, I. (2013) Systematic Vertebral Fracture Assessment in Symptomatic Postmenopausal Women. Bone, 52, 176-180. https://doi.org/10.1016/j.bone.2012.09.023

[48] Fujiwara, S., Kasagi, F., Yamada, M. and Kodama, K. (1997) Risk Factors for Hip Fracture in Japanese Cohort. Journal of Bone and Mineral Research, 12, 998-1004. https://doi.org/10.1359/jbmr.1997.12.7.998

[49] Trémollières, F.A., Pouilles, J.M., Drewniak, N., Laparra, J., Ribot, C.A. and Dargent-Molina, P. (2010) Fracture Risk Prediction Using BMD and Clinical Risk Factors in Early Postmenopausal Women: Sensitivity of the WHO FRAX Tool. Journal of Bone and Mineral Research, 25, 1002-1009. https://doi.org/10.1002/jbmr.12

[50] Honkanen, R.J., Honkanen, K., Kröger, H., Alhava, E., Tuppurainen, M. and Saarikoski, S. (2000) Risk Factors for Perimenopausal Distal Forearm Fracture. Osteoporosis International, 11, 265-270. https://doi.org/10.1007/s001980050291

[51] Paganini-Hill, A., Atchison, K.A., Gornbein, J.A., Nattiv, A., Service, S.K. and White, S.C. (2005) Menstrual and Reproductive Factors and Fracture Risk: The Leisure World Cohort Study. Journal of Women's Health (Larchmt), 14, 808-819. https://doi.org/10.1089/jwh.2005.14.808

[52] Hillier, T.A., Rizzo, J.H., Pedula, K.L., et al. (2003) Nulliparity and Fracture Risk in Older Women: The Study of Osteoporotic Fractures. Journal of Bone and Mineral Research, 18, 893-899. https://doi.org/10.1359/jbmr.2003.18.5.893

[53] Taylor, B.C., Schreiner, P.J., Stone, K.L., et al. (2004) Long-Term Prediction of Incident Hip Fracture Risk in Elderly White Women: Study of Osteoporotic Fractures. Journal of the American Geriatrics Society, 52, 1479-1486. https://doi.org/10.1111/j.1532-5415.2004.52410.x

[54] Kauppi, M., Heliövaara, M., Impivaara, O., Knekt, P. and Jula, A. (2011) Parity and Risk of Hip Fracture in Postmenopausal Women. Osteoporosis International, 22, 1765-1771. https://doi.org/10.1007/s00198-010-1392-1

[55] Nguyen, T.V., Jones, G., Sambrook, P.N., White, C.P., Kelly, P.J. and Eisman, J.A. (1995) Effects of Estrogen Exposure and Reproductive Factors on Bone Mineral Density and Osteoporotic Fractures. The Journal of Clinical Endocrinology \& Metabolism, 80, 2709-2714. https://doi.org/10.1210/jcem.80.9.7673413 